\title{
COMPARATIVE LEVELS OF RIFAMPICIN IN SERUM AND SALIVA IN TUBERCULOSIS PATIENTS BY HPLC METHOD
}

\author{
Mandapakala Gopala Krishna Murthy'1, Tarigopula Pramod Kumar ${ }^{2}$ \\ ${ }^{1}$ Associate Professor, Department of Pulmonary Medicine, Kakatiya Medical Collage, Hanamkonda, Warangal, Telangana. \\ ${ }^{2}$ Assistant Professor, Department of Pulmonary Medicine, Gandhi Medical College, Securdrabad, Telangana.
}

\section{ABSTRACT}

\section{BACKGROUND}

Tuberculosis is a deadly disease, which can be cured only by anti-tuberculosis therapy. Anti-tuberculosis therapy will be effective only when the drugs are given in ideal combinations and doses, which can achieve adequate Minimal Inhibitory Concentrations (MIC) in the tissues. Slow response to Tuberculosis (TB) therapy in spite of good adherence may lead to prolonged infectiousness or acquired drug resistance, which further burdens public health systems by extending treatment duration. Hence, there is a need for measuring therapeutic drug concentrations in patients on anti-tuberculosis therapy, at least in special comorbid conditions like diabetes mellitus and HIV. High Performance Liquid Chromatography (HPLC) is a sensitive and specific method of measuring rifampicin levels.

\section{OBJECTIVE}

To measure the levels of rifampicin in serum and saliva by HPLC technique and look for their correlation.

\section{METHODS}

Twenty pulmonary tuberculosis patients were divided into two groups - Group 1 (14 patients who were given 600 mg of rifampicin orally in a single dose on the day of sampling) and Group 2 ( 6 patients given $450 \mathrm{mg}$ of rifampicin). Thirteen samples of saliva and seven samples of blood (serum) were collected over a period of $24 \mathrm{hrs}$. at fixed intervals from the time of drug administration in each subject. Samples are subjected to HPLC to measure rifampicin levels.

\section{RESULTS}

The peak heights obtained at different concentrations of the drug were plotted against the drug concentration and looked for their statistical significance.

\section{CONCLUSION}

In the present study, the concentrations of the drug in serum and saliva after administering single oral dose of 600/450 mg of rifampicin were correlating well throughout the time period. The required minimal inhibitory concentration of rifampicin $(0.5$ $\mu \mathrm{g} / \mathrm{mL}$ ) is achieved in serum and saliva in both groups. Thus monitoring of rifampicin levels in saliva can be recommended in place of serum drug monitoring whenever needed.

\section{KEYWORDS}

Tuberculosis, Rifampi in, HPLC, Chromatography, Urine, Serum, Saliva, Chemotherapy.

HOW TO CITE THIS ARTICLE: Murthy MGK, Kumar TP. Comparative levels of rifampicin in serum and saliva in tuberculosis patients by HPLC method. J. Evolution Med. Dent. Sci. 2016;5(33):1827-1831, DOI: 10.14260/jemds/2016/430

\section{INTRODUCTION}

Tuberculosis disease continues to represent a global threat with an estimated 9 million incident cases and 1.5 million deaths in 2013 attributable to Mycobacterium tuberculosis infection. ${ }^{[1]}$ In the developed countries, in spite of attaining a good control of the disease in the latter half of 20th century with the advent of chemotherapy, resurgence of disease has occurred due to increased prevalence of HIV infection. Antituberculosis therapy will be effective only when the drugs are given in ideal combinations, in doses which can achieve adequate Minimal Inhibitory Concentrations (MIC) in the tissues and for appropriate duration without interruption. The minimal inhibitory concentration of rifampicin in body fluids is about $0.5 \mu \mathrm{g} / \mathrm{mL}$. $^{[2]}$ Non-adherence to the anti-tuberculosis

Financial or Other, Competing Interest: None.

Submission 20-02-2016, Peer Review 31-03-2016,

Acceptance 06-04-2016, Published 25-04-2016.

Corresponding Author:

Dr. Mandapakala Gopala Krishna Murthy,

12-11-208, Warasiguda,

Secunderabad,

Telangana.

E-mail:imkrishna@rediffmail.com

DOI: $10.14260 /$ jemds $/ 2016 / 430$ treatment is the prime cause of treatment failure and drug resistance, which can be overcome with directly observed therapy.

Slow response to Tuberculosis (TB) therapy in spite of good adherence may lead to prolonged infectiousness or acquired drug resistance, which further burdens public health systems by extending treatment duration. ${ }^{[3-5]}$ Serum concentrations of anti-tuberculosis drugs have been associated with many factors such as malabsorption, smoking status, comorbidity of diabetes mellitus and HIV, alcohol consumption, hypoalbuminaemia, calculated creatinine clearance by Cockcroft-Gault equation for EMB (CockcroftGault, 1976), liver and kidney dysfunctions, low dose per kilogram of body weight, changes in drug formulation, age and gender (UM et al 2007; Mcllleron et al, 2006; Narita et al, 2001).

Rifampicin anti-tuberculosis activity was first demonstrated in 1967. At the time this study was done, i.e. 1997, metabolic and pharmacokinetic properties of rifampicin were extensively studied in serum body tissues and body fluids in normal subjects by High Performance Liquid Chromatography (HPLC) technique.[6] But most of the clinical studies in patients on anti-tuberculosis therapy utilized 
microbiological techniques to determine the concentrations of drug at different sites of the body.[7] By these techniques, the levels of the drug estimated includes not only the parent drug, but also its active metabolites. But HPLC method is both highly sensitive as well as specific technique of measuring a drug in body fluids, as it can estimate the parent drug and its metabolites separately. Since very few studies were done prior to the present study by using HPLC in clinical setting, we had decided to do the present study of measuring rifampicin levels in serum and saliva with HPLC technique. We hypothesise that if a significant correlation is present in serum and salivary levels of rifampicin, we can use salivary drug estimations in place of serum drug levels for therapeutic drug monitoring as it is easy to get saliva samples from patients.

\section{AIM OF THE STUDY}

This study is intended to know the distribution of rifampicin in serum and saliva after administering a single dose of $600 \mathrm{mg}$ (or) $450 \mathrm{mg}$ of rifampicin in TB patients and whether there is any correlation that can be drawn between the serum and saliva levels.

\section{PATIENTS AND METHODS}

This prospective correlation study was done on the patients admitted between August and October 1997 to the Government Chest Diseases and Tuberculosis Hospital, Hanamkonda. Twenty pulmonary tuberculosis patients were selected for the study.

\section{Inclusion Criteria}

1. Newly diagnosed sputum positive pulmonary tuberculosis patients.

2. Old pulmonary tuberculosis patients who came with relapse, who had recently turned positive for sputum AFB on direct smear.

\section{Exclusion Criteria}

1. Those patients suffering with comorbid conditions like diabetes mellitus, HIV disease and other conditions causing malabsorption syndrome, kidney and liver dysfunction.

After admission into the hospital, thorough clinical examination and following investigations were carried out on the subjects.

- Sputum examination for acid fast bacilli by direct microscopy and concentration smear.

- Standard chest skiagram PA view and additional views as required.

- Nutritional parameters like weight, height and serum proteins.

- Blood urea/serum creatinine.

- Liver function tests.

As the study is intended to know the correlation between serum and saliva levels of rifampicin, we made two groups of subjects depending on the dosage, so as to look for the correlation with variable drug concentrations.

\section{Group}

Includes those subjects who were given $600 \mathrm{mg}$ of rifampicin orally in a single dose on the day of sampling; 14 patients were selected into this group.

\section{Group II}

Includes those subjects who were given $450 \mathrm{mg}$ of rifampicin orally in a single dose on the day of sampling; 6 patients were selected into this group.

All the patients had no history of rifampicin intake at least for 3 months prior to the sampling day. This is to prevent the chances of auto-induction effect of previous rifampicin therapy.[8]

\section{Assay Method and Equipment}

The present study is done to estimate the levels of rifampicin in serum and saliva of pulmonary tuberculosis patients after administration of $600 \mathrm{mg}$ or $450 \mathrm{mg}$ of the drug orally in single dose. Assay of rifampicin in saliva and serum were performed by a modified High Performance Liquid Chromatography (HPLC) method of old field et al on Shimadzu HPLC unit equipped with a $15 \mathrm{cms} \times 4.6 \mathrm{~mm}$ octadecylsilane reverse phase column and electrochemical detector. The mobile phase was $60 \%$ aqueous methanol containing $50 \mathrm{mmol} / \mathrm{L}$ potassium nitrate at a flow rate of $1 \mathrm{~mL} / \mathrm{min}$ at room temperature. An electrochemical detector with a glassy carbon working electrode was used at an oxidizing potential of $0.45 \mathrm{v}$ and sensitivity of $4 \mathrm{nA}$.

\section{Collection of Samples}

450/600 mg of Rifampicin is administered orally depending upon the group to which the subject belongs. The drug is administered on the day of sampling on empty stomach. About 5 minutes before scheduled time of collection of sample, patient was asked to wash his/her mouth thoroughly. About 4$5 \mathrm{~mL}$ of saliva is collected into a wide mouthed screw capped bottle. Venous blood is collected at the midpoint of the period of salivary collection; 13 samples of saliva and 7 samples of blood were collected over a period of $24 \mathrm{hrs}$. at fixed intervals from the time of drug administration in each subject. Patient is allowed to take food about $3 \mathrm{hrs}$. after the drug administration. Blood sample is centrifuged to separate serum, which is transferred into screw capped bottles. The serum and saliva samples placed in deep freeze at $-20^{\circ} \mathrm{C}$ until assay after appropriate coding.

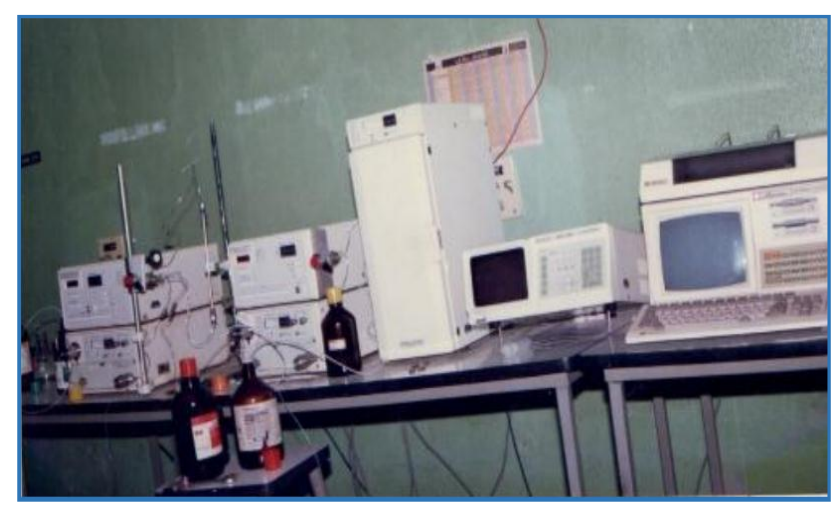

Picture 1

Shimadzu HPLC unit by which Rifampicin levels in serum and saliva has been assayed.

\section{PROCEDURE}

Samples were analysed within $48 \mathrm{hrs}$. of the collection. Serum $(0.5 \mathrm{~mL}) /$ Saliva $(2 \mathrm{~mL})$ was transferred into a screw capped test tube. To this $0.5 \mathrm{~mL}$ of methanol was added and mixed well. To that $3 \mathrm{~mL}$ of chloroform was added and were shaken 
for 15 minutes on a rotary shaker. The test tubes were centrifuged for 10 minutes at high speed; $2.5 \mathrm{~mL}$ of chloroform layer was separated and placed in a clear dry test tube and dried under vacuum. The residue was reconstituted in $100 \mu \mathrm{L}$ of which was injected onto the column. A standard graph was prepared by adding $100 \mathrm{ng}$ to $2.5 \mu \mathrm{g}$ of rifampicin to serum $(0.5 \mathrm{~mL}) /$ saliva $(2 \mathrm{~mL})$ obtained from untreated volunteers. These standard samples were treated in the same manner as the test samples.

The peak heights obtained at different concentrations of the drug were plotted against the drug concentration. The slope of this plot determined by the method of least squares regressive analysis was used to calculate rifampicin concentration in the unknown samples. The reproducibility of this assay method was tested and coefficient of variation of each concentration was lower than $7 \%$. Rifampicin concentration values in serum and saliva at different time intervals for all patients were tabulated and analysed.

On analysis of the results, it was found that some of the values were found to be varying from the rest of the values. By a method called ' $\mathrm{Z}$ ' test, these discrepant values were determined and these values were ignored in deriving the means and standard deviation. The values were marked under the respective tables as discordant data.

$$
\begin{array}{|cl}
\hline \mathrm{Z} \text { ' Test: } & \\
\mathrm{Z}=\frac{\mathrm{M}-\mathrm{V}}{\mathrm{S} . \mathrm{D} .} \geq 1.96 \\
\mathrm{M} & =\quad \text { Mean of the values in a group. } \\
\mathrm{V} & =\quad \text { Value to be checked. } \\
\mathrm{SD} & =\quad \text { Standard deviation of the values in a group. }
\end{array}
$$

If ' $\mathrm{Z}$ ' value is more than 1.96 , then that value can be discarded for further calculations. These values may be seen because of inter-individual variations or due to technical problems in the procedures.

\section{Statistical Analysis and Descriptive Values}

The mean body weights of patients in group I and group II were 38.57 (Range: 33-47) kg and 36 (Range: 33-40) kg respectively. The mean heights of patients in group I and group II were $159.57(170-145) \mathrm{cm}$ and $157(148-165) \mathrm{cm}$ respectively.

\begin{tabular}{|c|c|c|}
\hline & Group 1 & Group 2 \\
\hline Number of Subjects (n) & 14 & 6 \\
\hline Number of Males & 12 & 5 \\
\hline Number of Females & 2 & 1 \\
\hline Mean Age in Years (SD) & $42.357(11.93)$ & $38.33(16.93)$ \\
\hline $\begin{array}{c}\text { Mean Height in cms } \\
\text { (SD) }\end{array}$ & $159.57(7.30)$ & $157(6.324)$ \\
\hline Mean Weight in kgs (SD) & $38.571(3.897)$ & $36(2.966)$ \\
\hline Sputum for AFB by D/S & 14 & 6 \\
\hline \multicolumn{2}{|c|}{ Table 1: Baseline Characteristics of the Study Groups } \\
\hline
\end{tabular}

\begin{tabular}{|c|c|c|c|c|c|c|c|}
\hline \multirow{2}{*}{ Patient } & \multicolumn{7}{|c|}{ Time in Hrs. } \\
\cline { 2 - 8 } & $\mathbf{0 . 5}$ & $\mathbf{1 . 0}$ & $\mathbf{2 . 0}$ & $\mathbf{3 . 0}$ & $\mathbf{7 . 0}$ & $\mathbf{1 2 . 0}$ & $\mathbf{2 4 . 0}$ \\
\hline Mean & 1.18 & 4.59 & 10.11 & 12.18 & 8.28 & 5.10 & 1.85 \\
\hline S.D. & 0.55 & 1.96 & 2.57 & 1.92 & 2.19 & 1.29 & 0.63 \\
\hline \multicolumn{7}{|c|}{ Sabjects (600 $\mathbf{~ m g ) ~}$} \\
\hline
\end{tabular}

Table 2 shows serum levels of rifampicin in group I patients. The peak drug concentrations were achieved in $85 \%$ of the patients at the end of $3 \mathrm{hrs}$. The levels increased up to 3 hrs. and declined thereafter. The mean peak serum concentration being $12.18 \mu \mathrm{g} / \mathrm{mL}$.

\begin{tabular}{|c|c|c|c|c|c|c|c|c|c|c|c|c|c|}
\hline \multirow{2}{*}{ Patient } & \multicolumn{13}{|c|}{ Time in Hrs. } \\
\hline & 0.5 & 1.0 & 1.5 & 2.0 & 2.5 & 3.0 & 4.0 & 5.0 & 7.0 & 8.0 & 12.0 & 13.0 & 24.0 \\
\hline Mean & 0.099 & 0.46 & 0.75 & 0.01 & 1.12 & 1.22 & 1.09 & 0.92 & 0.84 & 0.73 & 0.51 & 0.45 & 0.16 \\
\hline S.D. & 0.062 & 0.19 & 0.17 & 0.26 & 0.19 & 1.92 & 0.21 & 0.17 & 0.21 & 0.16 & 0.12 & 0.13 & 0.06 \\
\hline
\end{tabular}

Table 3 shows mean salivary levels of rifampicin in group I patients. The peak drug concentrations were achieved in $85 \%$ of the patients at the end of $3 \mathrm{hrs}$. The mean peak saliva concentrations of the drug being $-1.22 \mu \mathrm{g} / \mathrm{mL}$.

\begin{tabular}{|c|c|c|c|c|c|c|c|}
\hline & \multicolumn{7}{|c|}{ Time in Hrs. } \\
\cline { 2 - 8 } & $\mathbf{0 . 5}$ & $\mathbf{1 . 0}$ & $\mathbf{2 . 0}$ & $\mathbf{3 . 0}$ & $\mathbf{7 . 0}$ & $\mathbf{1 2 . 0}$ & $\mathbf{2 4 . 0}$ \\
\hline Mean & 0.57 & 2.35 & 6.17 & 7.99 & 5.56 & 3.58 & 1.08 \\
\hline S.D. & 0.39 & 3.05 & 2.82 & 1.98 & 0.76 & 0.82 & 0.22 \\
\hline \multicolumn{7}{|l}{ Table 4: Mean Serum Levels of Rifampicin $(\boldsymbol{\mu g} / \mathbf{m L}$ ) in Group-II Subjects (450 $\mathbf{m g})$} \\
\hline
\end{tabular}

Table 4 shows mean serum levels of rifampicin in group II patients. The peak drug concentrations were achieved in $66 \%$ of the subjects at the end of $3 \mathrm{hrs}$. The mean peak serum concentration of the drug being $-7.99 \mu \mathrm{g} / \mathrm{mL}$.

\begin{tabular}{|c|c|c|c|c|c|c|c|c|c|c|c|c|c|}
\hline & \multicolumn{13}{|c|}{ Time in Hrs. } \\
\hline & 0.5 & 1.0 & 1.5 & 2.0 & 2.5 & 3.0 & 4.0 & 5.0 & 7.0 & 8.0 & 12.0 & 13.0 & 24.0 \\
\hline Mean & 0.08 & 0.21 & 0.45 & 0.62 & 0.72 & 0.84 & 0.76 & 0.68 & 0.6 & 0.52 & 0.37 & 0.27 & - \\
\hline S.D. & 0.01 & 0.24 & 0.29 & 0.28 & 0.23 & 0.22 & 0.18 & 0.14 & 0.1 & 0.808 & 0.08 & 0.07 & - \\
\hline
\end{tabular}

-Inadequate Samples.

Table 5 shows mean salivary levels of rifampicin

$(\mu \mathrm{g} / \mathrm{mL})$ in group II subjects. Peak drug concentrations $\left(\mathrm{C}_{\max }\right)$ 
were achieved in $83.3 \%$ of patients at the end of $3 \mathrm{hrs} . \mathrm{C}_{\max }$ being 0.84 . The drug is not detectable in the $24 \mathrm{hrs}$. saliva sample.

In group I patients, the mean serum concentrations and saliva concentrations of the drug are achieved at the end of 3 hrs., but the value is $1.23 \mathrm{mcg} / \mathrm{mL}$ in saliva which is considerably low when compared to serum which is 12.18 $\mathrm{mcg} / \mathrm{mL}$. In group II patients, peak serum concentrations were achieved at 3 hours with peak concentration being 8.15 $\mathrm{mcg} / \mathrm{mL}$. The corresponding peak salivary concentrations in these patients being $0.84 \mathrm{mcg} / \mathrm{mL}$. Ratio of saliva and serum concentration remained 0.1 throughout the time in group I patients, whereas in group 2 patients it varied from 0.11 to 0.31, though a better uniformity was found in mean saliva/serum concentrations at 3,7 and 12 hours interval.

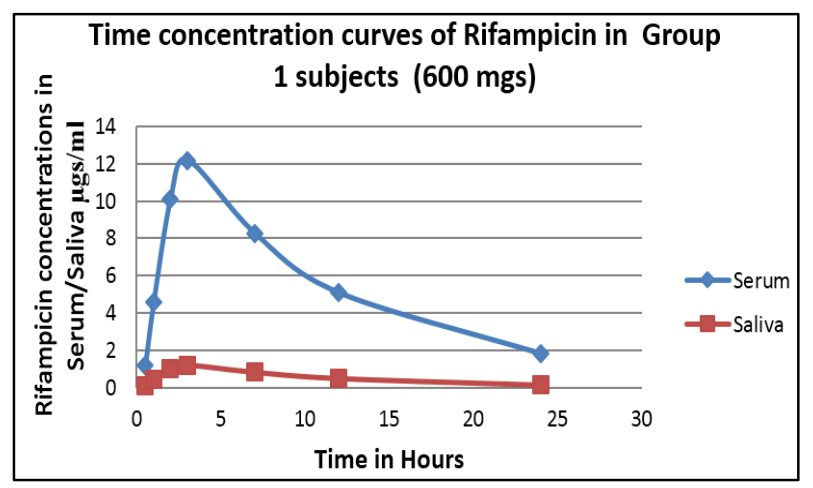

Graph 1

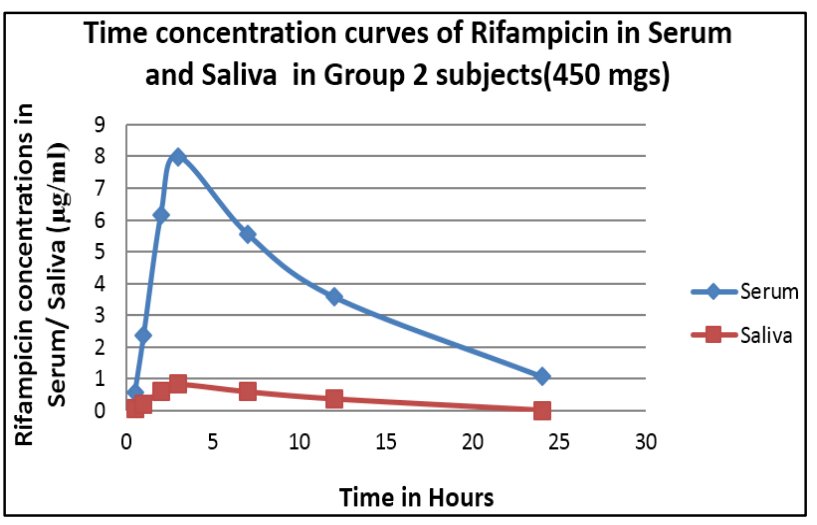

Graph 2

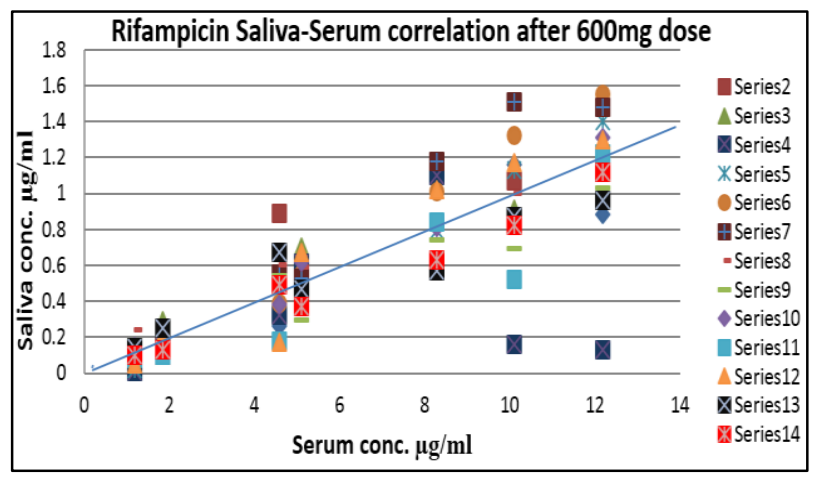

Graph 3

(Series 1 to $14=$ Patients 1 to 14 )

Graph-3 shows saliva (SL)/serum (SE) ratio of the drug in group I patients. The mean SL/SE ratio is 0.1 . This ratio remained at 0.1 at all-time intervals after drug administration This gives a clue that a definite correlation (Overall ' $r$ ' value 0.842 ) exists between serum and saliva drug levels.

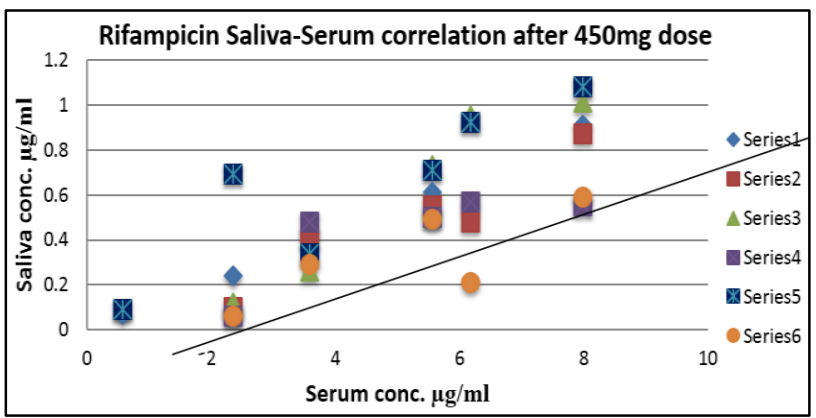

Graph 4

(Series 1 to $6=$ Patients 1 to 6 )

Graph 4 depicts SL/SE ratio of the drug in group II patients. Mean SL/SE ratio varied from 0.11 to 0.31 . There is a better uniformity found in the mean SL/SE ratios at $3 \mathrm{hrs}$., 7 hrs. and 12 hrs. interval. The overall ' $r$ ' value for group II patients is 0.554 .

The mean saliva/serum (SL/SE) ratio of the drug in the present study remained constant throughout the time period in group I patients and in later part of the time concentration curve in group II patients, whereas the mean SL/SE ratio values at $8 \mathrm{hrs}$. were almost double that at $1 \mathrm{hr}$. As mentioned earlier minimal inhibitory concentration against most susceptible mycobacterium is $0.5 \mu \mathrm{g} / \mathrm{mL}$, was found to be present in saliva and serum in both group I and group II subjects.[2]

\begin{tabular}{|c|c|c|c|c|c|}
\hline & Cmax & tmax & AUC & t1/2 & MRT \\
\hline Mean & 1.23 & 2.89 & 15.13 & 7.25 & 12.24 \\
\hline S.D. & 0.17 & 0.29 & 2.81 & 2.43 & 3.16 \\
\hline Table 6: Pharmacokinetics of Rifampicin in Saliva in \\
Group-I Subjects (600 mg)
\end{tabular}

$\mathrm{Cmax}=$ peak concentrations $\mu \mathrm{g} / \mathrm{mL}, \mathrm{T} \max =$ peak time, AUC $=$ Area under the curve, $t 1 / 2=$ half-life of the drug, $M R T=$ mean residence time in hours.

Table 6 shows the pharmacokinetics of rifampicin in group I subject. The mean $\mathrm{C}_{\max }$ is 1.23 and the mean salivary half-life of the drug being $7.25 \mathrm{hrs}$.

\begin{tabular}{|l|l|l|l|l|l|}
\hline & Cmax & Tmax & AUC & t1/2 & MRT \\
\hline Mean & 0.84 & 2.91 & 10.59 & 8.56 & 13.88 \\
\hline S.D. & 0.21 & 0.20 & 4.36 & 7.48 & 10.39 \\
\hline \multicolumn{6}{|c|}{ Table 7: Pharmacokinetics of Rifampicin in Saliva in } \\
Group-II Subjects (450 $\mathbf{~ m g ) ~}$
\end{tabular}

$\mathrm{Cmax}=$ peak concentrations $\mu \mathrm{gs} / \mathrm{mL}, \mathrm{T} \max =$ peak time, AUC $=$ Area Under the Curve, $t 1 / 2=$ half-life of the drug, MRT = Mean Residence Time in hours.

Table 7 shows the pharmacokinetics of rifampicin in group II subjects. The mean $\mathrm{C}_{\max }$ is 0.84 and the mean salivary half-life of the drug being $8.56 \mathrm{hrs}$.

\section{DISCUSSION}

After subjecting the samples to the previously mentioned procedure, the values for the concentration of drug in the samples were tabulated and analysed. 
Apart from the saliva/serum ratios, pharmacokinetics of rifampicin in saliva is evaluated for group I and group II subjects. Rifampicin metabolites 25-o-desacetyl rifampicin and rifampicin quinone were found to have small amounts of antimicrobial activity. Some of the studies done on the basis of microbiological techniques used the degree of antimicrobial activity to correlate with the concentration of the drug and/or its active metabolites in the sample. The concentration values obtained by these studies therefore includes both the levels of free drug and its active metabolites. In an assay based on high performance liquid chromatography, the drug can be estimated independent of its other metabolites in a given sample. Lecaillon et al performed assay of rifampicin and three of its metabolites in human plasma, urine and saliva by using HPLC method.[6] In the present study only rifampicin levels were assayed. No efforts were made to assay the levels of different metabolites of rifampicin in serum or saliva.

In the study done by Gurumurthy et al, the concentration in saliva were much lower than those in serum and the mean peak concentration $\left(\mathrm{C}_{\max }\right)$ in the two body fluids 0.9 and 8.5 $\mu \mathrm{g} / \mathrm{mL}$ respectively. ${ }^{[7]}$ In the present study, the mean peak concentrations in group I patients is 0.84 and $8.56 \mu \mathrm{g} / \mathrm{mL}$ in saliva and serum respectively which are correlating with the above study. The lower values in saliva compared to serum can be explained on the basis of high protein bound (80\%) nature of rifampicin. The elimination half-life $\left(t_{1 / 2}\right)$ of rifampicin was $5.1 \mathrm{hrs}$. on the basis of concentration in saliva according to Gurumurthy et al, whereas in the present study the $t_{1 / 2}$ of rifampicin was $5.5 \mathrm{hrs}$. in group II patients and $7.25 \mathrm{hrs}$. in group I patient, which are also found to be correlating well. In the present study, the value of $t_{\max }(3 \mathrm{hrs}$.) is close to that in the study done by Aberghina et al etc., which is 2.84, but slightly deviating from the values of P. Gurumurthy et al study, which is 2 hrs.[7]

As shown in Graph 3, the mean SL/SE ratio is 0.1 in group I patients. This ratio remained at 0.1 at all-time intervals after drug administration. This gives a clue that a definite correlation (Overall ' $r$ ' value 0.842 ) exists between serum and saliva drug levels. Similarly, as per the graph 4 , the mean SL/SE ratio varied from 0.11 to 0.31 in group II patients. There is a better uniformity found in the mean SL/SE ratios at $3 \mathrm{hrs}$., 7 hrs. and 12 hrs. interval. The overall ' $r$ ' value for Group II patients is 0.554 . This may be due to inadequate salivary samples at $0.5 \mathrm{hrs}$. interval. The variance in the SL/SE ratio occurred mainly during the drug absorption phase, that is the drug might have been absorbed at different absorption rates in different individuals. The variability in the absorption rates may be explained on the basis of interindividual differences, food, drugs and malabsorption syndromes. ${ }^{[9-13]}$

Thus in the present study, the concentrations of the drug in serum and saliva after administering single oral dose of $600 / 450 \mathrm{mg}$ of rifampicin were correlating well throughout the time period. The minimal inhibitory concentrations of the drug are found in saliva and serum in both the groups. Thus according to this study, monitoring of rifampicin levels in saliva can be recommended in place of serum drug monitoring. However, as anti-tuberculosis drugs are given in combination to the tuberculosis patients, further studies are needed to compare the levels of rifampicin in saliva, other body fluids and tissues with HPLC method after giving rifampicin in combination with other anti-tuberculosis drugs.

\section{CONCLUSION}

In the present study, the concentrations of the drug in serum and saliva after administering single oral dose of $600 / 450 \mathrm{mg}$ of rifampicin were correlating well throughout the time period. The minimal inhibitory concentrations of the drug are found in saliva and serum in both the groups. Thus according to this study, monitoring of rifampicin levels in saliva can be recommended in place of serum drug monitoring.

\section{REFERENCES}

1. World health organization. Global Tuberculosis report 2014 Report No. WHO/HTM/TB/2014.08. Geneva, WHO 2014.

2. Jen Suo, Cheng-Erh Chang, Tao Ping Lin, et al. Minimal inhibitory concentrations of isoniazid, rifampin, ethambutol, and streptomycin against mycobacterium tuberculosis strains isolated before treatment of patients in Taiwan. American Review of Respiratory Disease 1988;138(4):999-1001.

3. Mehta JB, Shantaveerapa H, Byrd RP, et al. Utility of rifampin blood levels in the treatment and follow-up of active pulmonary tuberculosis in patients who were slow to respond to routine directly observed therapy. Chest 2001;120(5):1520-4.

4. Nijland HM, Ruslami R, Stalenhoef JE, et al. Exposure to rifampin is strongly reduced in patients with tuberculosis and type 2 diabetes. Clin Infect Dis 2006;43(7):848-54.

5. Heysell SK, Moore JL, Keller SJ, et al. Therapeutic drug monitoring among slow responders to tuberculosis therapy in a state control program. Emerg Infect Dis 2010;16(10):1546-53.

6. Lecaillon JB, Febvre N, Metayer JP, et al. Quantitative assay of rifampicin and three of its metabolites in human plasma, urine and saliva by high HPLC. J Chromatography 1978;145:319-24.

7. Gurumurthy P, Rahman F, Narayana AS, et al. Salivary levels of isoniazid and rifampicin in tuberculous patients. Tubercle 1990;71(1):29-33.

8. Nitti V, Delli Veneri F, Meola G. Rifampicin blood serum levels and half-life during prolonged administration in tuberculous patients. Chemotheraps 1972;17(2):121-9.

9. Toman K. Tuberculosis case finding and chemotherapy WHO, Geneva 2002;184.

10. Furesz S, Scotti R, Pallanza R, et al. Rifampicin: a new rifamycin. Arznei-forsch 1967;17(5):534-7.

11. Hagelund $\mathrm{CH}$, Wahlen P, Eidsaunet W. Absorption of rifampicin in gastrectomized patients. J Resp Dis 1977;58:241-8.

12. Polasa K, Krishnaswamy K. Effect of food on bioavailability of rifampicin. J Clin Pharmacol 1983;23(10):433-7.

13. Wasson KR, Harris JO. The treatment of tuberculosis in the presence of malabsorption syndromes. Am Rev Resp Dis 1976;113:57. 